\title{
Removal of Violet Crystal from Aqueous Solution by Limon Peel Powders from Adamawa Region of Cameroon
}

\author{
Kagongbe D., ${ }^{3}$ Adjia Zangue H*.,${ }^{1,2}$ Inna S., ${ }^{2}$ Noumi Guy B., ${ }^{3}$ Villieras F., ${ }^{1}$ and Ebio Nko'o G., ${ }^{3}$ \\ ${ }^{1}$ Laboratoire Interdisciplinaire des Environnements Continentaux (LIEC) UMR 7360 CNRS - \\ Université de Lorraine 15 Avenue du Charmois, F-54500 @ F Villieras ; \\ ${ }^{2}$ National School of Agro-Industrial Sciences (ENSAI) University of Ngaoundere B.P. 455 Adamaoua, CAMEROON; \\ ${ }^{3}$ Department of Chemistry, Faculty of Science (FS) University of Ngaoundere B.P. 454 Ngaoundere, CAMEROON.
}

\begin{abstract}
The pollution of wastewater from industrial discharges is a serious problem in several developing countries, particularly Cameroon. This pollution can cause damaging effects on the environment and human health. For this purpose, several physicochemical processes for the treatment of wastewater have been implemented, in particular that of adsorption. The present study consists in using a new natural adsorbent based on silt skin powders in order to treat industrial and artisanal discharges. The tests were carried out on Crystal violet which is a basic cationic dye. The influence of physicochemical adsorption experimental parameters was studied, namely contact time, mass, $\mathrm{pH}$, concentration and temperature. These tests showed a remarkable elimination from the first 20 minutes. The kinetic models of pseudo-first and second order have been studied. The Langmuir and Freundlich isotherms were also studied. However, the experimental results showed that the adsorption of Crystal violet by the biosorbent reached an elimination rate of $81.36 \%$ at $\mathrm{pH} 6.15 \pm 2$ and at a temperature of $25 \pm 1{ }^{\circ}$ C. The adsorption of Crystal violet has made it possible to understand that the pseudo-second-order kinetic model better describes the adsorption of confirmed crystal violet by a correlation coefficient $R^{2}$ of greater than 0.999 . The Freundlich isotherm better describes the adsorption of Crystal violet with a correlation coefficient greater than 0.90 . Thermodynamic parameters such as $\Delta G^{\circ}, \Delta S^{\circ}$ and $\Delta H^{\circ}$ have shown that the crystal violet adsorption mechanism on silt skin powders is physical, spontaneous and exothermic and between 293K and 333K. Therefore the skins of silt can be valued as adsorbents in general and in particular as biosorbent in the treatment of industrial effluents. Analysis of the FT-IR spectrum shows the presence of numerous functional groups such as phenol, amide, amine, carboxylic acid, alkene, alkyne.
\end{abstract}

Key words: - Lemon peel, Crystal violet, adsorption, Adamawa region.

\section{INTRODUCTION}

Water is a vital resource for man; his health and development depend on it. But because of the increase of its consumption and its use by the individuals and the industrialists, this one is subject of the pollution which thus generates wastewater which is rejected in an anarchic way and without treatment (AGENCE EAU / France, 1994), which contributes significantly to the contamination of the water table in particular and the environment in general. In developing countries, the activities of artisans such as tanneries, dyeing companies ... are the ones that cause water pollution (Adjia et al., 2014); Thus marking whose dyes as major pollutant of these wastewater. Crystal violet, which is a basic cationic dye (Shawabkeh and Tutunji, 2003), once dissolved in water, is sometimes difficult to treat because they have a synthetic origin and a complex molecular structure that makes them more stable and difficult to be biodegradable (Forgacs et al., 2004). Several methods have been developed to treat this wastewater and are: physical, chemical and biological (Rangabhashiyam et al., 2013). But all these techniques seem very expensive for the developing countries, which do not control this water pollution, lack of less expensive and adequate treatment.

The technique of adsorption which is the most favorable method for the elimination of dyes in general and particular Crystal purple has become an analytical method of choice, very effective and simple in its use. The study of the present art, several solid materials (clays, zeolites, activated aluminas, sludge, biomasses, agricultural residues, industrial by-products and activated carbon, etc.) that can be used in processes for the depollution of wastewater (Faouzia, 2014). The valorization of agricultural residues without generating pollutants is a great challenge and is recommended for sustainable industrial development in order to preserve the environment (Khalfaoui, 2012). Waste resulting from the processing of raw materials generally has little or no market value (Faouzia, 2014). Thus, the use of these by-products as materials aims to valorize them and prevent the possible consequence that is harmful for the environment and health. Moreover, for the adsorption of dyes, the most sought after materials are those with a high content of tannin and lignin such as bark (orange) and sawdust (Faouzia, 2014).

So far, no study has been conducted on silt skins in wastewater remediation. The skins of lemons in general and in particular the skins of silt are one of the most important skins of the citrus fruit, because the silt appears as one of the most important in the ingredients of the kitchen, a garnish, like juice in lemonade , carbonated beverage and others (Bhatnagar et al., 2009). To do this, to avoid visual pollution by these skins of silt, they can be upgraded after extraction of the juices as abundant and less expensive adsorbents or biosorbents in wastewater treatment (Bhatnagara et al., 2010). 
The present work makes it possible to prove the adsorptive potential of silt skins in the treatment of wastewater to improve the living conditions of the populations.

\section{2 .MATERIAL AND METHODS}

\subsection{Preparation of the biosorbent.}

The silt skins used as biosorbents in the context of our work concerning the adsorption of Crystal violet in batch mode are obtained after peeling the silt fruits purchased from the village women in the local markets of Dang (N'Gaoundéré-Cameroun). These wet skins are washed several times with tap water and then rinse several times with distilled water. After washing, these skins of slimes are dried for 24 hours between 40 and $50^{\circ} \mathrm{C}$ inside a
MEMMERT brand electric dryer followed by grinding. After grinding, the powders of silt skins are obtained after sieving, the particle size of which is between $200 \mu \mathrm{m}$ and 2 $\mathrm{mm}$ using a sieve of ISO-3310-1 mark. BODY: $200 \mathrm{~mm} \times$ $50 \mathrm{~mm}$, made in Germany.

\subsection{Preparation of the adsorbate}

Crystal violet in figure 1, a monovalent cationic basic dye with molecular formula $\mathrm{C}_{25} \mathrm{H}_{30} \mathrm{~N}_{3} \mathrm{Cl}$. In dye classification it is classified as C.I 42555 and class: basic dye 3. It is molecular weight of $407,98 \mathrm{~g} / \mathrm{mol}$. Stock solution of Crystal violet $1000 \mathrm{mg} / \mathrm{L}$ was prepared in double-distilled water and the experimental solutions of the concentration were obtained by successive dilution.

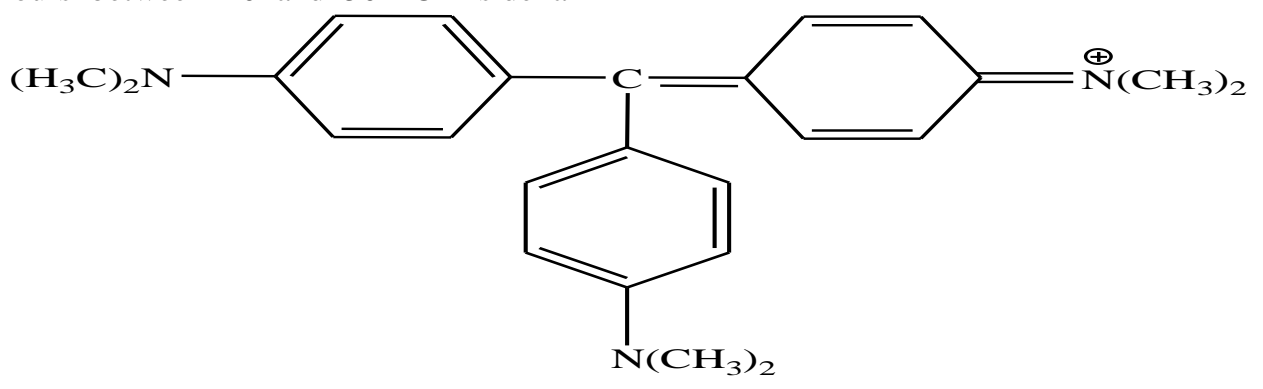

Figure 1: Structure of Crystal violet

\subsection{PHYSICO-CHEMICAL CHARACTERISTICS OF THE BIOSORBENT}

2.3.1. Determination of the specific surface area by the methylene blue method (AFNOR, 1992)

The principle of this method is to determine the necessary amount of methylene blue to cover a mono-molecular layer of the outer and inner surface of biosorbent in water. A mass of approximately $1 \mathrm{~g}$ of finely ground biosorbent (200 $\mu \mathrm{m}$ ) was mixed in a $100 \mathrm{ml}$ beaker, $20 \mathrm{ml}$ of distilled water to suspend by an AVW-ADVANCED type magnetic stirrer for a few minutes. Then, the latter will be assayed by a methylene blue solution of known mass concentration (drop by drop) until the persistence of the light blue halo which surrounds the central deposit of the spot formed on the wattman filter paper.

\section{3.2. Expression of results}

The overall area is related to the volume of methylene blue added. Knowing that by definition, the overall area is proportional to the mass of methylene blue adsorbed per unit area of a given solid material. According to the theory, a molecule of methylene blue occupies an average surface area of $120 \mathrm{~A}^{2}$, so it is possible to calculate the mass area (specific area) via the Avogadro number. The formula is as follows:

$$
\text { Ss }=\frac{C \times V \times 6,02210^{23} \times 1,210^{-18} \mathrm{~m}^{2}}{M}(1)
$$

Where $C(\mathrm{~mol} / \mathrm{l})$ is the molar concentration of $\mathrm{V}(\mathrm{L})$, methylene blue volume, $\mathrm{M}(\mathrm{g})$ is the mass of biosorbant.

\subsection{Determination of equilibrium $\mathrm{pH}$}

The equilibrium $\mathrm{pH}$ will be determined by contacting $1 \mathrm{~g}$ of biosorbent (200 .mu.m) with $100 \mathrm{ml}$ of distilled water (pH =6.7). The sample will be stirred at $300 \mathrm{rpm}$ for 24 hours. The $\mathrm{pH}$ measurements will be made every $25 \mathrm{~min}$ using a Schott Gerate $\mathrm{pH}$ meter until equilibrium, at the end of $24 \mathrm{~h}$ , the equilibrium $\mathrm{pH}$ is measured again.

\subsection{Determination of pH of zero charges ( $\mathrm{pHpzc}$ )}

The $\mathrm{pHpzc}$ or $\mathrm{pH}$ of zero charge corresponds to the $\mathrm{pH}$ value for which the net charge of the surface of the adsorbents is zero (Wibowo et al., 2007). This parameter is very important in adsorbent phenomena especially when electrostatic forces are applied in the mechanism. The method for the determination of the zero charge $\mathrm{pH}$ consists in placing $50 \mathrm{ml}$ of a solution of $\mathrm{NaCl}(0.01 \mathrm{M})$ in closed vials after adjusting the $\mathrm{pH}$ of each (value between 2 and 12 ) by addition of $\mathrm{NaOH}$ solution $(0.1 \mathrm{~N})$ or $\mathrm{HCl}$ $(0.1 \mathrm{~N}) .50 \mathrm{mg}$ of biosorbent sample to be characterized are then added to each of the flasks. The suspensions are stirred at room temperature for 24 hours and the final $\mathrm{pH}$ is then determined. Then, we look at a graph $\Delta \mathrm{pH}=\mathrm{f}(\mathrm{pHi})$; the intersection of the curve with the axis passing through zero gives the pHpzc.

\subsection{Study of adsorption}

The study of the adsorption of Crystal violet by the native silt skin powder was done in batch mode at room temperature. This study was done by shaking a series of volumetric flasks containing crystal violet solutions of varying concentration between $5 \mathrm{mg} / \mathrm{L}$ and $30 \mathrm{mg} / \mathrm{L}$. The samples were made at time intervals of between 10 and 80 
minutes, thus making it possible to determine the contact time between the adsorbate and the adsorbent. The solutions are removed from the stirrer after stirring for 30 minutes and then filtered using wattman filter paper and then proceed to read the optical density of the samples using an UV-visible spectrophotometer of VWRADVANCED brand. The adsorption study is carried out at initial $\mathrm{pH}$ conditions 6.15 ; at room temperature $25^{\circ} \mathrm{C}$.

The study of the influence of $\mathrm{pH}$ is carried out by varying the $\mathrm{pH}$ values from 2 to 10 and the adjustment was done using the $\mathrm{NaCl}(0.1 \mathrm{~N})$ and $\mathrm{HCl}(0.1 \mathrm{~N})$ solutions. The elimination percentage is given by the following formula:

$$
\frac{C i-C t}{C i} \times 100(2)
$$

$\mathrm{C}_{\mathrm{i}}$ : initial concentration of Crystal violet, $\mathrm{C}_{\mathrm{t}}$ : final concentration

The isotherms are given by varying the concentrations of the solution of the Crystal violet from 5 to $30 \mathrm{mg} / \mathrm{L}$. The calculation of the quantity adsorbed ${ }^{q_{\theta}}(\mathrm{mg} / \mathrm{g})$ according to the relation according to: $q_{\theta}(\mathrm{mg} / \mathrm{g})=\frac{(\mathrm{Co}-\mathrm{Ce}) \times V}{m}(3)$

Where $C_{o}$ is the initial concentration, $C_{e}$ is the equilibrium concentration, $\mathrm{V}(\mathrm{ml})$ is the volume of the concentration in purple Hook, $\mathrm{m}(\mathrm{g})$ is the mass of biosorbant.

\section{RESULTS AND DISCUSSION}

\subsection{Caracterisation Physico-Chemical of Biosorbent}

According to the table 1, the specific and very low surface area compared to the specific surface area of commercial activated charcoal based on $1158 \mathrm{~m}^{2} / \mathrm{g}$ skins obtained by the B.E.T method is found. The low surface area of our biosorbent can be explained either by the nature of our samples or by the method of determining this specific surface. As for the equilibrium $\mathrm{pH}$, an equilibrium $\mathrm{pH}$ of about 4.9 is obtained. This $\mathrm{pH}$ balance allows us to know the exact $\mathrm{pH}$ of our material, which also has an acid character proving its membership in lemons.

Table 1: The specific Area and equilibrium $\mathrm{pH}$

$\begin{array}{r}\hline \text { Specific area } \\ \hline 6,93 \\ \hline\end{array}$

\subsection{IR-FT analysis}

The Figure 2 above shows a $3350 \mathrm{Cm}^{-1}$ band characteristic of the $\mathrm{OH}$ group of alcohol. Also a band between 2001$1943 \mathrm{Cm}^{-1}$ indicating the presence of a triple bond of the alkynes. The band lying between $1454-1416 \mathrm{Cm}^{-1}$ indicates the presence of aromatic double bonds and the alcohols vibration band $(-\mathrm{OH})$. The peak at 1210 is characteristic of the phenol groups and located between $1187-1155 \mathrm{Cm}^{-1}$ indicating the deformation of the group - $\mathrm{OH}$ and $-\mathrm{COOH}$, deformation vibration of $\mathrm{COC}$ of the ether group and the presence of the phosphate group (PO) caused the activating agent which is phosphoric acid $\mathrm{H}_{3} \mathrm{PO}_{4}$. The peak located at $1000 \mathrm{Cm}^{-1}$ indicates the presence of the double bond $\mathrm{CC}$ of the alcenes. The peak at $872 \mathrm{Cm}^{-1} 1$ indicates the presence of the group NC- amides and $724 \mathrm{Cm}^{-1}$ indicates that of amine -NH. The peak appeared between $494-500 \mathrm{Cm}^{-1}$ shows the deformation of the halogenes. In fact, we can say through this spectrum FT-IR it presence of groups such as alcohol, aromatic, alkyne, alcene, amide, amine, phenol.

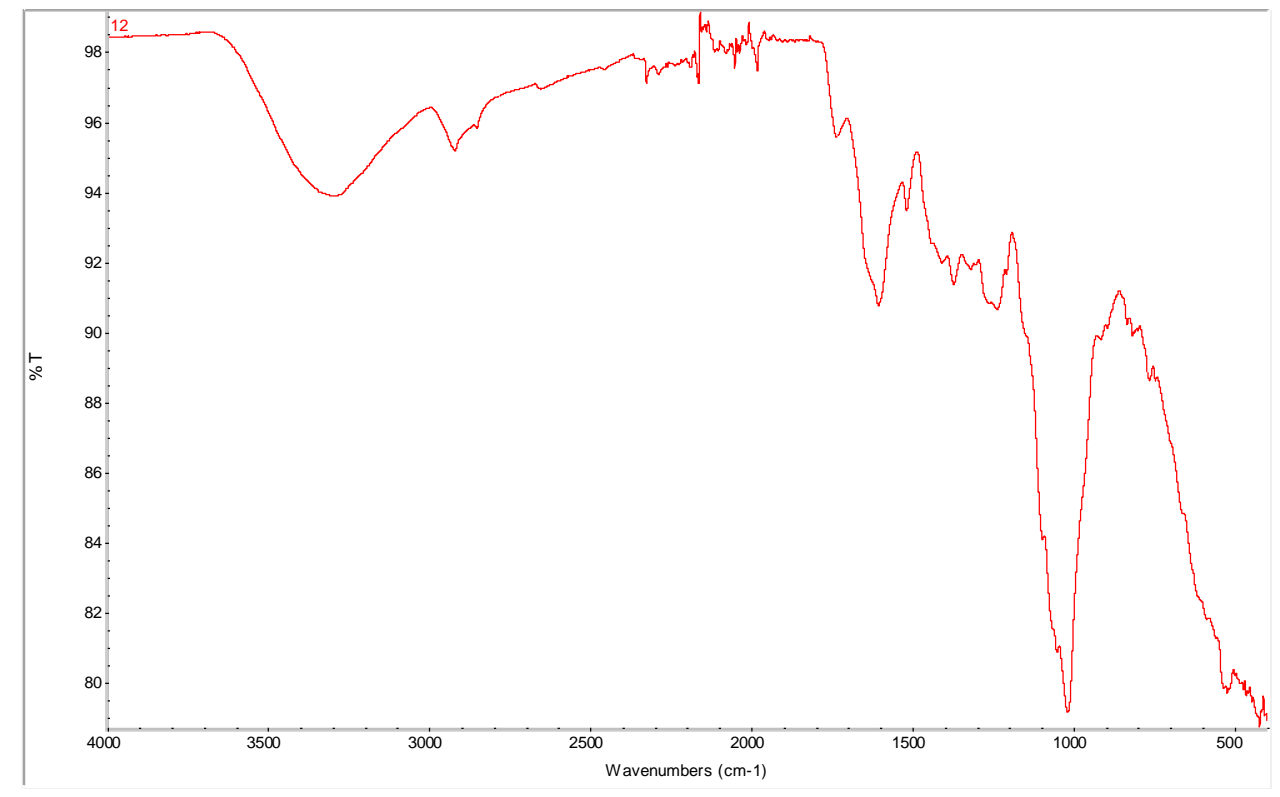

Figure 2: The FT-IR spectrum of the skin powder of citrus limonium (silt). 
3.3. The pH of zero powder load of dried silt skins.

In figure 3, the $\mathrm{pH}$ at which the charge of the solid surface is zero is mentioned as the zero point of charge (pHpzc). Above pHpzc the external charge of the adsorbent is negative (Khormaei et al., 2007), the nature of our adsorbents can be acidic or basic depending on the pHpzc values, so the pHpzc depends on the origin of the precursor and of the preparation method which can be chemical and physical, the pHpzc is also a good indicator of the chemical and electrical properties of the functional groups on the surface of our adsorbents (Baccar et al., 2012). According to this graph, we find the value of the pHpzc of our biosorbent of the order of 5.8. This result is in agreement with the other researchers like Singh and Sukla in 2015. However, the slight differences observed in the pHpzc values can be explained by the nature of our precursors, the method of preparation (Baccar et al., 2012).

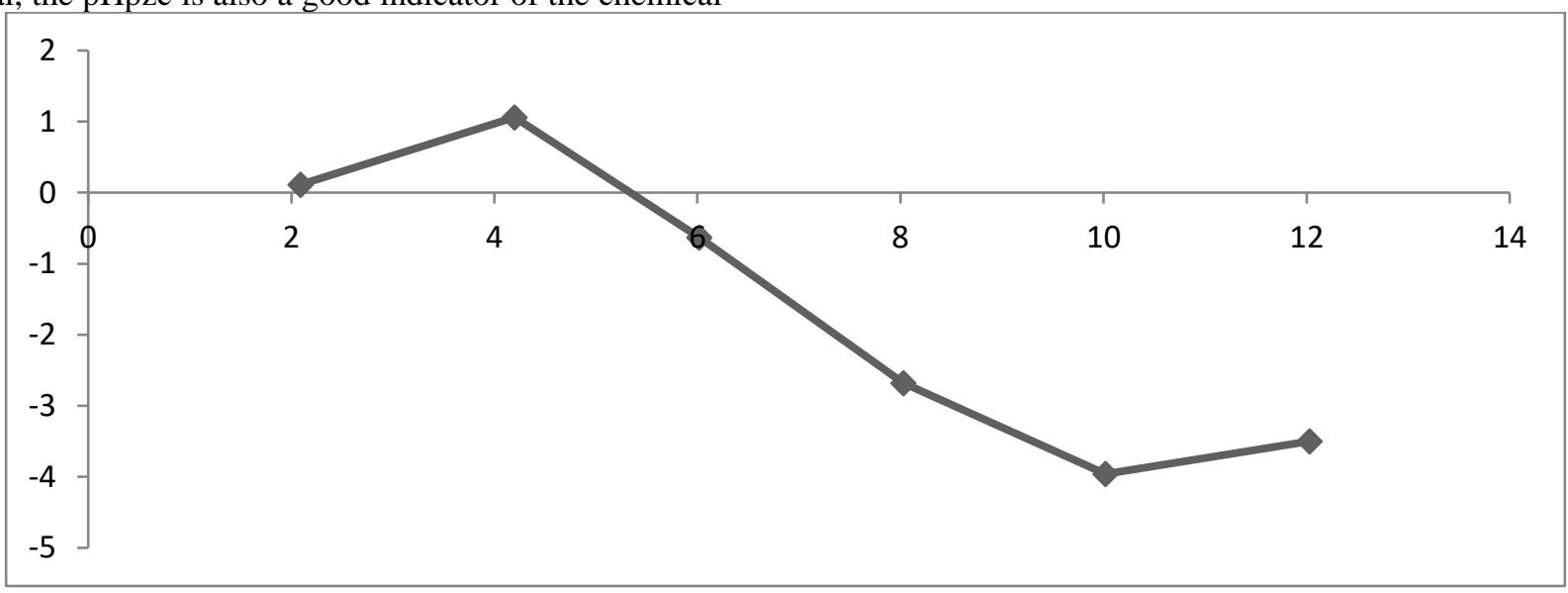

Figure 3: The $\mathrm{pH}$ of zero powder load of dried silt skins.

\subsection{Establishment of the adsorption spectrum of Crystal} violet in $U V$-visible

The adsorption spectrum of Crystal violet in UV-visible was made by a spectral sweep between $320 \mathrm{~nm}$ and $590 \mathrm{~nm}$ of a Crystal violet solution at $50 \mathrm{mg} / \mathrm{L}$ (Lin et al., 2011).
This spectrum in figure 4 indeed shows us a maximum wavelength which lies in the range $557 \mathrm{~nm}$ and $590 \mathrm{~nm}$ characterized by a peak around $586 \mathrm{~nm}$. So we considered this value of $586 \mathrm{~nm}$ for the rest of our work

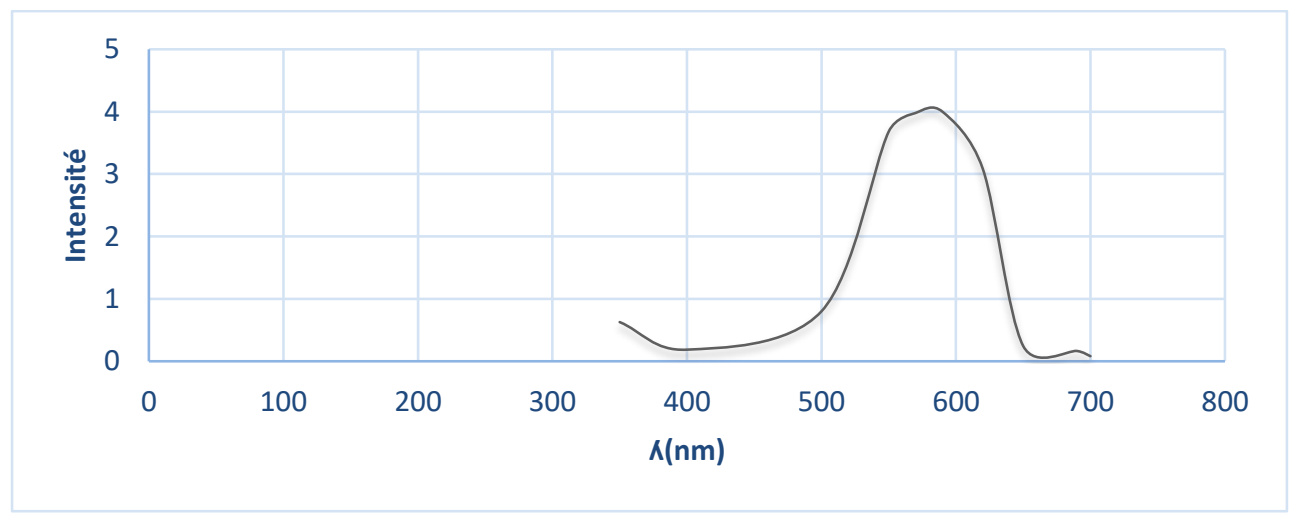

Figure 4: The UV-visible adsorption spectrum of Crystal violet

\subsection{The influence of contact time}

This Figure 5 represents the percentage of eliminations as a function of the contact time, where the shape of the curves shown is typical of that of saturation but with a fairly high Crystal violet adsorption rate during the first $\mathbf{2 0}$ minutes before decreasing and then tending towards saturation (equilibrium plateau). This can be explained by the fact that initially the adsorption sites are vacant, therefore easily accessible to Crystal violet molecules, hence a higher rate of adsorption, in addition to the fact that the concentration gradient between the solution and the liquid-solid interface is quite high at the beginning of the contacting of the solid and liquid phases.

However, after the initial period, adsorption becomes less due to slower diffusion of the species dissolved through the pores (Joel et al., 2007). The rapid removal of crystal violet molecules is of significant importance, as this will facilitate the use of reduced volumes of adsorbents and will ensure the efficiency and economy of the process. 


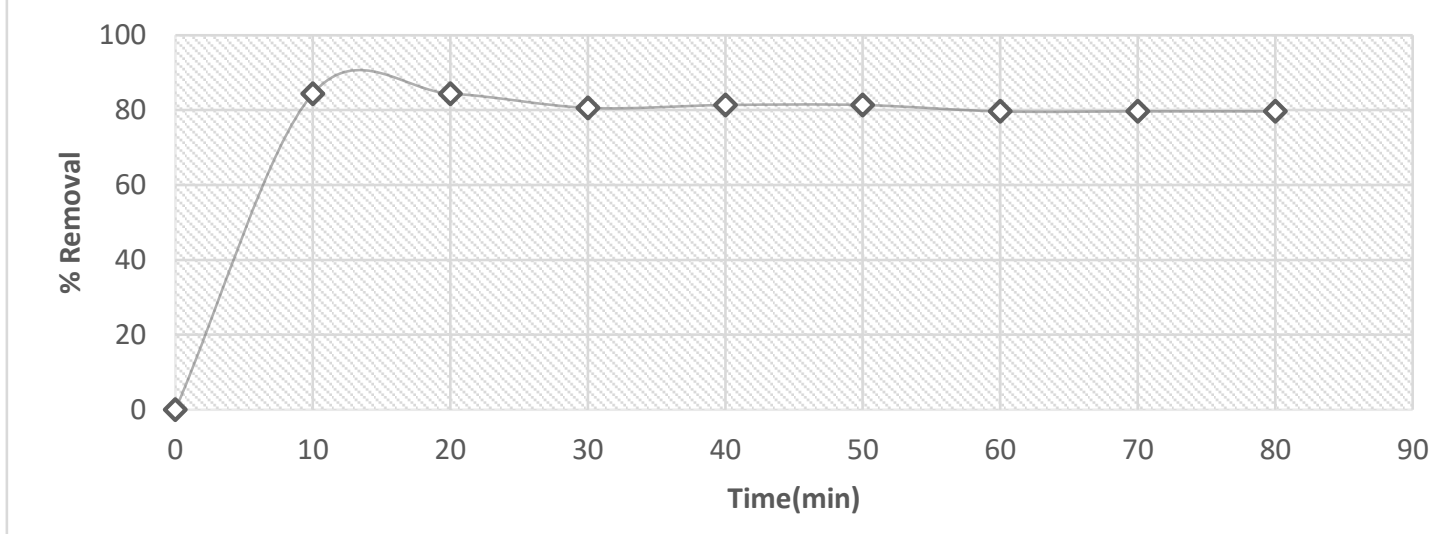

Figure 5: Influence of contact time on $\mathrm{Cv}$ adsorption $\left(\mathrm{C}=5 \mathrm{mg} / \mathrm{L}, \mathrm{m}=0.1 \mathrm{~g}, \mathrm{pH}=6.15, \mathrm{~T}=25^{\circ} \mathrm{C} \mathrm{d}=200 \mu \mathrm{m}\right)$.

\subsection{The influence of the mass of the biosorbant}

It emerges from this figure 6 that the adsorbed quantities decrease with increasing mass. Indeed, the interaction between the adsorbent molecules can cause the desorption of crystal violet molecules, narrow sites of the adsorbent (Manohar et al., 2002). On the other hand, when the mass of biosorbant increases, an aggregation / agglomeration of the particles of the biosorbents is formed, thus causing a decrease in the specific surface area (Mohan et al., 2006); this may explain the low adsorbed quantities of Crystal violet when the mass of the biosorbent increases. The decrease in the adsorbed quantity would also be due to a high availability of the exchangeable adsorption sites or the specific surface (Rais, 2009). However, other authors have worked on the same dye and found the results similar to (Nour et al., 2014, Patil et al., 2011).

Indeed, the amount adsorbed for a mass $0.1 \mathrm{~g}$ is maximum for the biosorbent, this value is of the order of $3.9448 \mathrm{mg} /$ $\mathrm{g}$. Thus, the mass of $0.1 \mathrm{~g}$ for the adsorbent will serve for the continuation of our work. But one of the factors that can influence the retention of Crystal violet molecules is its $\mathrm{pH}$.

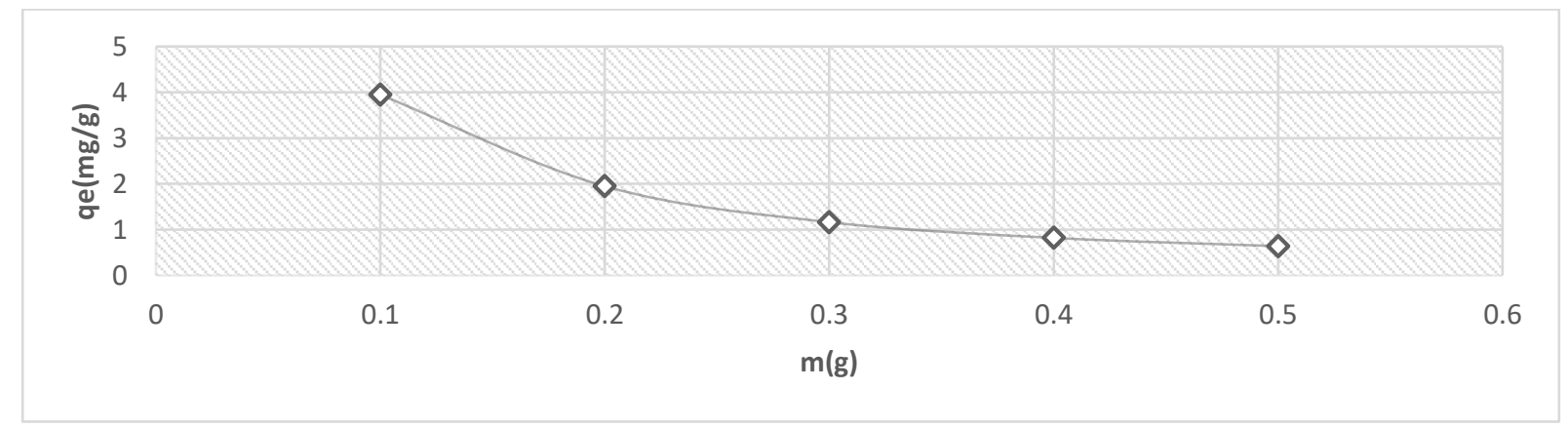

Figure 6 : Influence of the mass of the three biosorbents on Crystal violet adsorption $\left(\mathrm{C}=5 \mathrm{mg} / \mathrm{L}, \mathrm{t}=30 \mathrm{~min}, \mathrm{pH}=6.15, \mathrm{~T}=25^{\circ} \mathrm{C} \mathrm{d}=200 \mu \mathrm{m}\right)$.

\section{7. $p H$ effect}

It is good that the $\mathrm{pH}$ is a very important parameter intervening in the processes of adsorption, for this we varied the $\mathrm{pH}$ over a range going from 2 to 12 . According to this figure 7, it is clear that the adsorption of the Crystal violet molecules by our biosorbent increases up to $\mathrm{pH} 5$; this would be due to the biosorbent surface which is negatively charged according to the pHpzc value, this can also be explained because at low $\mathrm{pH}$ values, the surface of the adsorbents would be surrounded by $\mathrm{H}^{+}$ions which increases the Crystal violet (cationic pollutant) ions interact with the adsorbent sites. Above pH 5 the adsorbed amount of Crystal violet by the barbant decreases slightly to $\mathrm{pH} 7$ caused by the decrease of $\mathrm{H}^{+}$ions, against the high $\mathrm{pH}$, the $\mathrm{H}^{+}$concentration decreases which generates good interaction between dye ions and surface sites (Khalfaoui, 2012). Similar results have been found by (Sakr et al. 2014). 


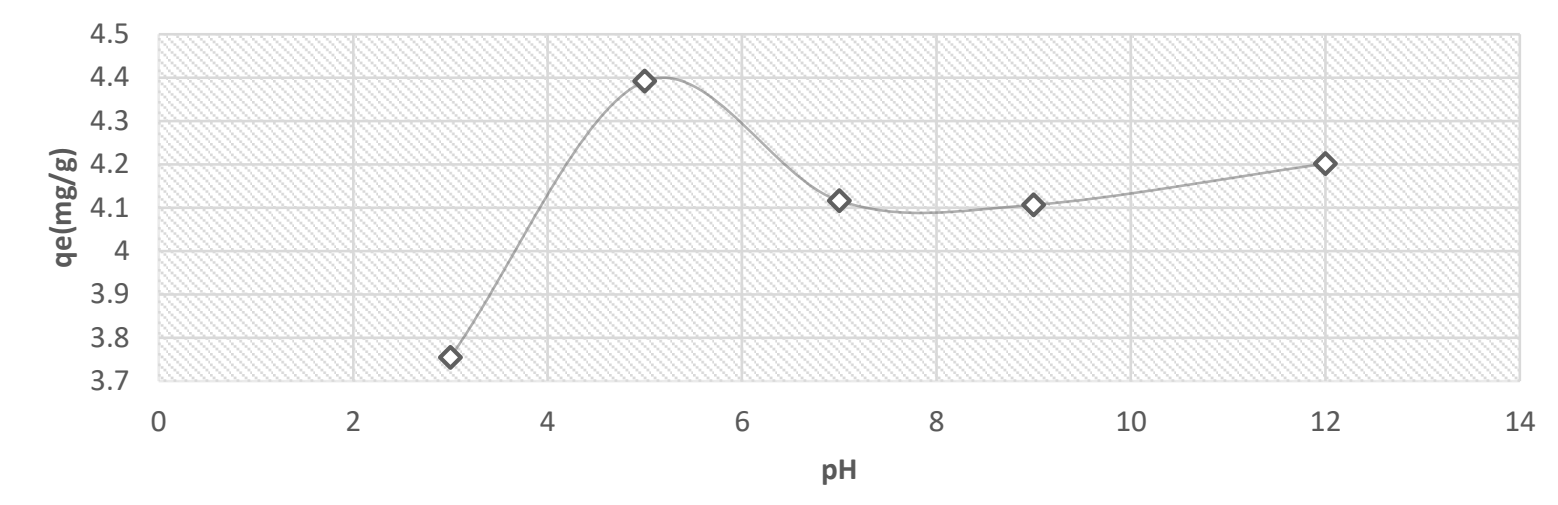

Figure 7 : Influence of $\mathrm{pH}$ on the Crystal violet adsorption capacity $\left(\mathrm{C}=5 \mathrm{mg} / \mathrm{L}, \mathrm{m}=0.1 \mathrm{~g}, \mathrm{t}=30 \mathrm{~min}, \mathrm{~T}=25^{\circ} \mathrm{C} . \mathrm{d}=200 \mu \mathrm{m}\right)$.

\subsection{Influence of concentration}

In order to study the effect of Crystal violet concentration on the percentage of elimination by the non-activated biosorbent (cf. figure 8), adsorption experiments were carried out in a concentration range varying between 5 and $30 \mathrm{mg} / \mathrm{l}$, for a mass $0.1 \mathrm{~g}$ of biosorbent, at a $\mathrm{pH}$ of 6.15 and at room temperature. To do this, we see that for our biosorbent the percentage of elimination increases with the crystal violet concentration until reaching a maximum value after a period of $20 \mathrm{~min}$, or $81.36 \%$ before being stabilized. This could be explained by the fact that initially the adsorption sites of the biosorbents were widely available to adsorb the Crystal violet molecules of low concentration or else a large availability of the active sites leading to an increase in the concentration gradient and the rate of diffusion of the analyte to the surfaces of the biosorbent. On the other hand, when the concentration of the analyte increases, the adsorption sites decrease and the percentage of eliminations decrease and become constant regardless of the Crystal violet concentration and this can be explained by the saturation phenomenon of the adsorption sites. on the surface of our biosorbents (Rais et al., 2017, Sayed et al., 2015).

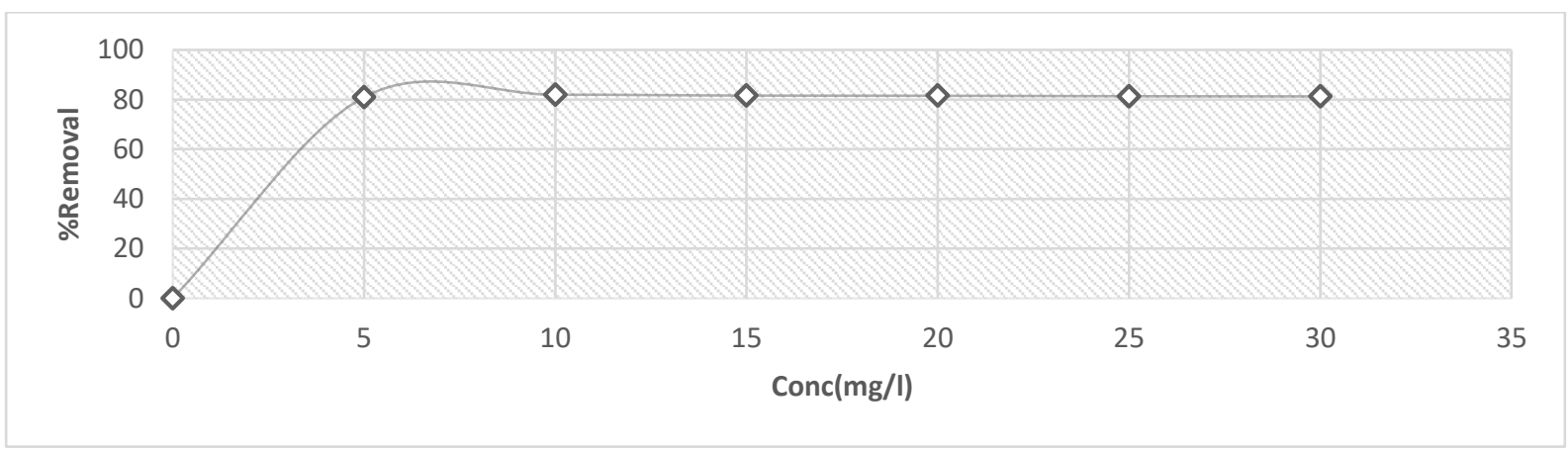

Figure 8 : The influence of the initial concentration on the adsorption of Crystal violet by the adsorbent $\left(\mathrm{m}=0.1 \mathrm{~g}, \mathrm{pH}=6.15, \mathrm{t}=30 \mathrm{~min}, \mathrm{~T}=25^{\circ} \mathrm{C} . \mathrm{d}=200\right.$

\subsection{Influence of temperature}

Figure 9 shows that the adsorption of $\mathrm{CV}$ by our adsorbent increases with temperature. The experiments were carried out for temperatures of $303,313,323 \mathrm{~K}$, for a concentration of $5 \mathrm{mg} / 1$ and for a mass of $0.1 \mathrm{~g}$ of biosorbent. The increase in temperature first favored the diffusion of the Crystal violet molecule through the boundary layer, then on the surface of the adsorbents and finally towards the inside of the pores of the adsorbents. Increasing adsorption with temperature can also be explained by increasing the numbers of adsorption sites generated by breaking internal bonds at the surface of the adsorbents.

Another explanation would be the favorable effect of temperature on the irreversible adsorption of these adsorbed Crystal violet molecules (Ryoo et al., 1999) or the desolation of Crystal violet molecules and an increase in active centers for adsorption. (Manohar et al., 2002). This result is similar to that obtained by Mouthe in 2017. 


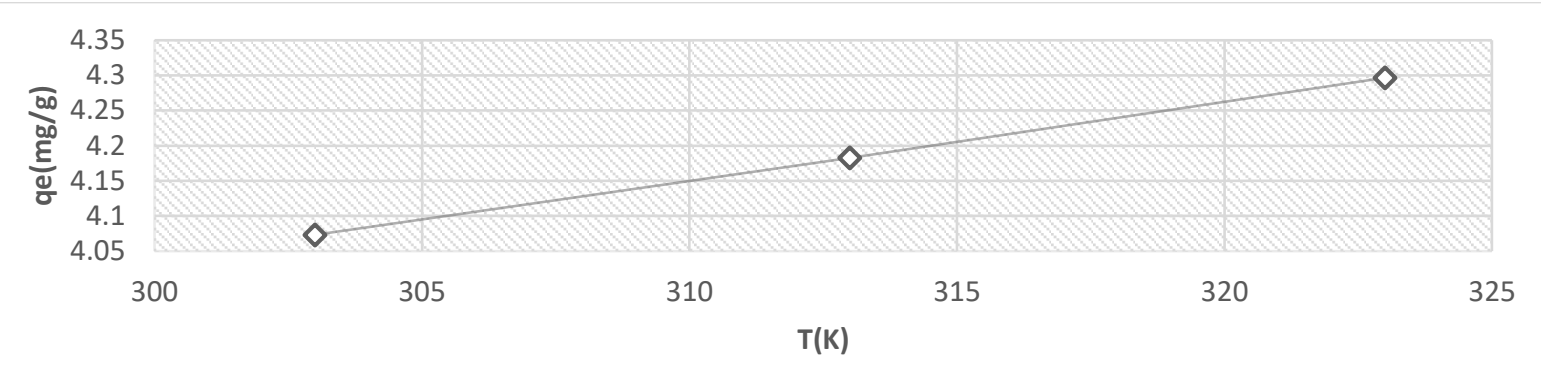

Figure 9: Influence of the temperature on the adsorption of Crystal violet $\left(\mathrm{C}=5 \mathrm{mg} / \mathrm{L}, \mathrm{m}=0.1 \mathrm{~g}, \mathrm{pH}=6.15, \mathrm{t}=30 \mathrm{~min}, \mathrm{~T}=25^{\circ} \mathrm{Cd}=200 \mu \mathrm{m}\right)$.

\subsection{Isotherms adsorption}

From Table 2 and Figure 10, we observe that the Freundlich model agreement with the experimental data is satisfactory for the adsorption of Crystal violet by our biosorbent. The $\mathrm{R}^{2}$ coefficient value presented in the following table shows that the Freundlich isothermal linear model is best for describing the adsorption of Crystal violet by the adsorbent. This model of Freundlich allows us to conclude that:

$\neg$ Crystal violet adsorption by our biosorbent consists of an exponential distribution of adsorptive site energies at the surface of biosorbent (Cooney, 1990);

$\neg$ It is also characterized by localized site adsorption;
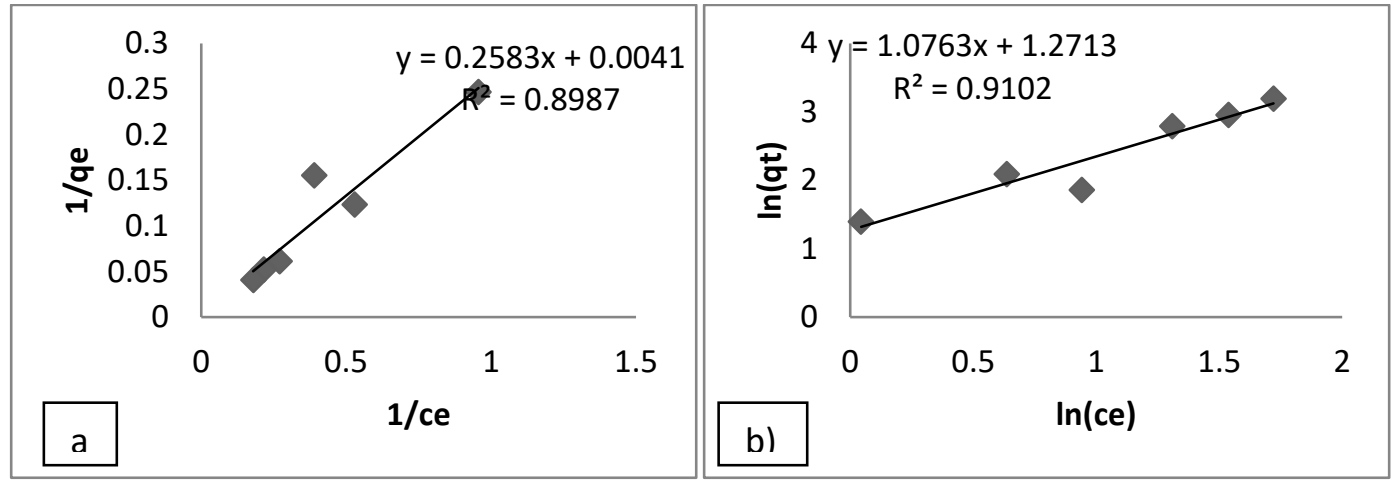

Figure 10: a) Langmuir isotherm and b) Freundlich isotherm.

Table 2: Summary of the isotherms of adsorption of Langmuir and Freundlich

\begin{tabular}{lccccc}
\hline \multicolumn{4}{l}{ Langmuir isotherm } & \multicolumn{3}{l}{ Freundlich isotherm } \\
\hline $\boldsymbol{q}_{\max (\mathrm{mg} / \mathrm{g})}$ & $\boldsymbol{K}_{\boldsymbol{L}(\mathbf{1} / \mathbf{m g})}$ & $\mathbf{R}^{2}$ & $K_{F}$ & $\frac{1}{n}$ & $\mathrm{R}^{2}$ \\
$\mathbf{3 , 8 7 1 4}$ & $\mathbf{6 3 , 0 0 1 0}$ & 0,8987 & 3,5654 & 1,0763 & $\mathbf{0 , 9 1 0 2}$ \\
\hline
\end{tabular}

\subsection{Kinetics of adsorption.}

The validity of the kinetic models is examined from the value of $\mathrm{R}^{2}$ of the linear regression coefficient reported in Table 3 above. It can be seen that the application of the pseudo-second-order kinetic model makes it possible to obtain regression coefficients greater than 0.90 in figure 11. Moreover, it is found that the values of $Q_{e}(\exp )$ and $Q_{e}$ (cal) are very close to one another for the biosorbent. This indicates that the adsorption is done in two steps:

$\neg$ The first step is the diffusion of Crystal violet molecules to the surface of the biosorbents

$\neg$ The second step is the interaction of Crystal violet molecules on the surface of the biosorbents. 
Table 3: Summary of the kinetic parameter pseudo-first and second order.

\begin{tabular}{llllllll}
\hline \multicolumn{2}{l}{ Kinetcs pseudo-first order } & \multicolumn{5}{l}{ Kinetics pseudo-second order } \\
\hline $\mathrm{R}^{2}$ & $\mathbf{Q e}(\mathbf{e x p})$ & $\mathbf{Q e}(\mathrm{cal})$ & $\mathrm{K}_{\mathbf{1}}\left(\boldsymbol{m i n}^{\mathbf{- 1}}\right)$ & $\mathbf{R}^{\mathbf{2}}$ & Qe (exp) & Qe (cal) & $\mathrm{K}_{\mathbf{2}}\left(\mathrm{g} \cdot \boldsymbol{m g}^{\mathbf{- 1}} \boldsymbol{m i n}^{\mathbf{- 1}}\right)$ \\
& & & & & & & \\
$\mathbf{0 , 9 0 1 3}$ & 3,7643 & 0,8175 & $\mathbf{0 , 0 4 8 3}$ & $\mathbf{0 , 9 9 9}$ & $\mathbf{7 3 , 7 6 4 3}$ & 3,745 & $\mathbf{0 , 5 8 6 2}$ \\
\hline
\end{tabular}

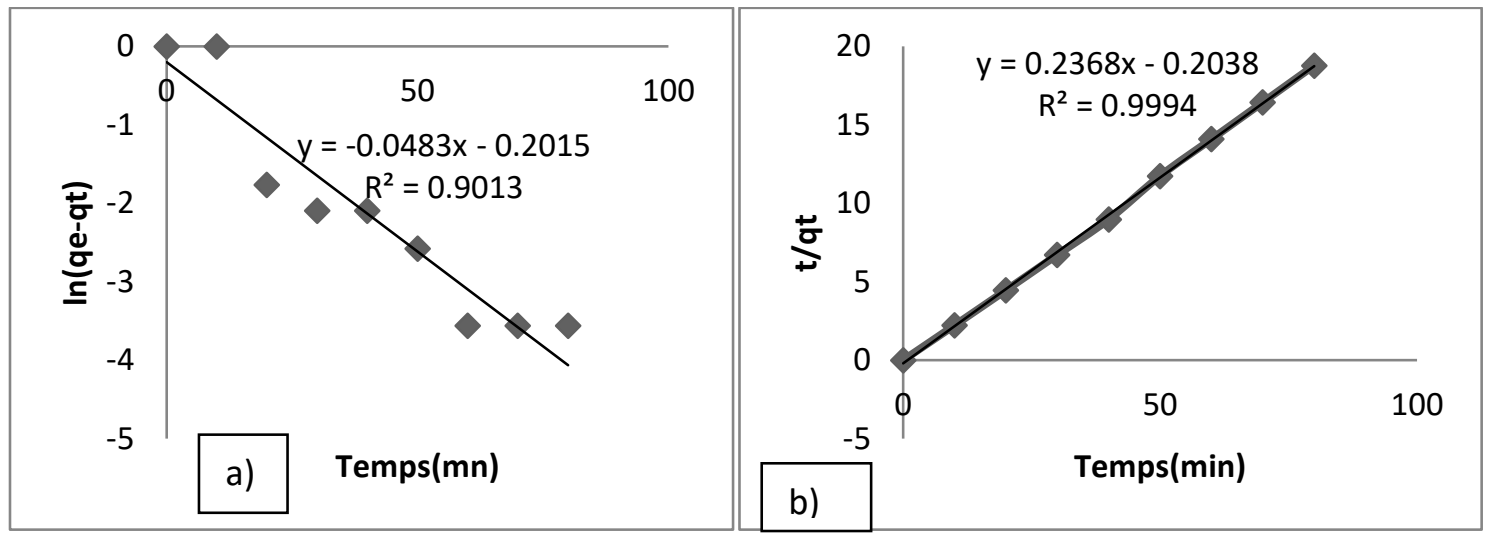

Figure 11: a) Kinetic pseudo first order; b) Kinetic pseudo second order

\subsection{Thermodynamic study.}

These Figure 12 and table 4 reveals that, the positive sign of enthalpy shows that the reaction between the crystal violet molecule and the biosorbent surface is exothermic. The increase in temperature thus serves to increase the diffusion of the crystal violet molecule to the surfaces of the adsorbent (Chun and Chen, 2002), the temperature then acting as a catalyst.

Positive values of $\left(\Delta \mathrm{rS}^{\circ}\right)$ indicate an increase in adsorption disorder; this is not possible because the adsorption involves a reduction of the adsorbed $\mathrm{Cv}$ molecule. $\left(\Delta \mathrm{rS}{ }^{\circ}\right)$ would then describe the total phenomenon including diffusion (Patil et al., 2011, Senthilkumaar et al., 2006).
Negative values $\left(\Delta \mathrm{rG}^{\circ}\right)$ show that the reaction is spontaneous. It can be seen that the values of $\left(\Delta \mathrm{rG}^{\circ}\right)$ decrease with increasing temperature. In addition, the values of $\left(\Delta \mathrm{rG}^{\circ}\right)$ are between -20 and $0 \mathrm{Kj} / \mathrm{mol}$, which allows us to justify that the adsorption of Crystal violet on the surface of the adsorbent is physical. Increasing the amount adsorbed with temperature indicates that the system needs energy to overcome the kinetic activation energy. The low values of $\left(\Delta \mathrm{rG}^{\circ}\right)$ indicate that the bonds are low in energy. So the intermolecular forces are those involved in the adsorption of Crystal violet by the adsorbents.

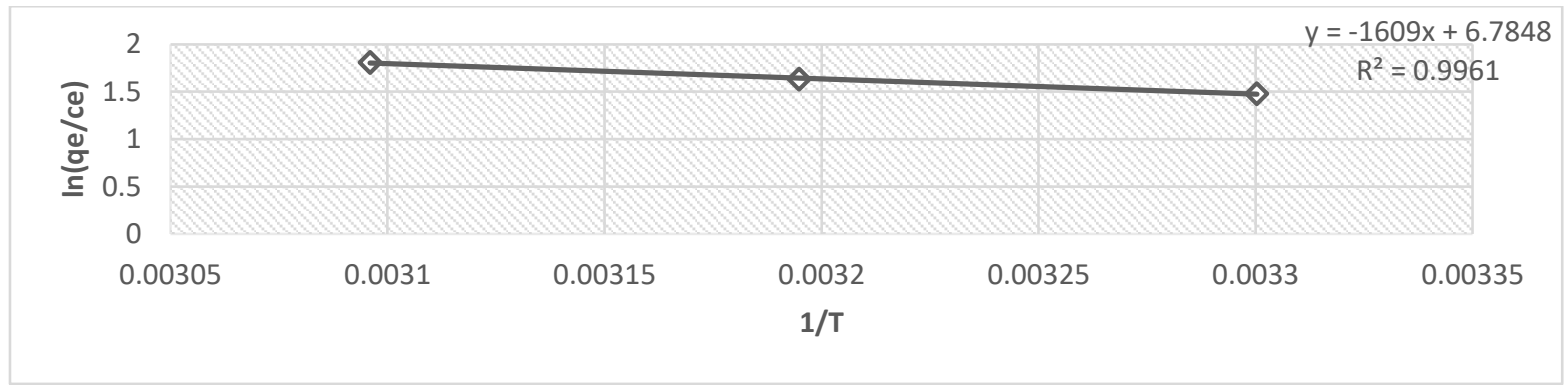

Figure 12: Linear form of thermodynamic parameter.

Table 4 : Summary of the values of constant thermodynamics

\begin{tabular}{lllll}
\hline $\mathrm{R}^{\mathbf{2}}$ & Températures & $\Delta \boldsymbol{r} \boldsymbol{G}^{\circ}\left(\frac{\boldsymbol{K j}}{\boldsymbol{m o l}}\right)$ & $\Delta \boldsymbol{r} \boldsymbol{H}^{\circ}\left(\frac{\boldsymbol{k j}}{\boldsymbol{m o l}}\right.$ & $\Delta \boldsymbol{r} \boldsymbol{S}^{\circ}\left(\frac{\boldsymbol{k j}}{\boldsymbol{m o l k}}\right)$ \\
\hline \multirow{2}{*}{$\mathbf{0 , 9 9 6 1}$} & $303 \mathrm{~K}$ & $-3,38$ & 13,38 & 0,056 \\
& $313 \mathrm{~K}$ & $-4,148$ & \\
\hline
\end{tabular}




\section{CONCLUSION}

The main objective of this work was to prove the natural adsorbent potential of silt skin powders in the treatment of wastewater containing Crystal violet to improve the living conditions of the populations.

In the light of the results, it appears that the properties of the silt skins have a very good Crystal violet retention capacity confirming a high affinity of Crystal violet to be adsorbed on the biosorbent. Linear regressions showed that kinetics are controlled by the pseudo-second-order kinetic model. This is clear and confirmed by the values of the correlation factors corresponding to each model. The effect of temperature on the retention of Crystal violet molecules by non-activated silt skin powders has shown that the process is exothermic and physical. The negative values of the Gibbs energy $(\Delta G<0)$ indicate that the adsorption process of this dye by the studied system is spontaneous.

\section{ACKNOWLEDGEMENTS}

I would like to thanks my project guide and other scientifics members of chemical engineering department in university of Nancy (France) and Ngaoundere (Cameroon) to provide necessary facilities.

\section{REFERENCES}

[1] Adjia Z. H., Villiéras F. et Kamga R., (2014). DEPOLLUTION DES EAUX USEES PAR LES ARGILES ALLUVIALES. Editions à EUE d'un livre, Référence du livre : 978-613-1-59387-1 (ISBN 978-613-1-59387-1); ISBN-10: 6131593876 ; EAN: 9786131593871 ; Maison d'édition: Editions universitaires europeennes ; Site Web: http://www.editionsue.com/ ; Publié le:18-09-2014.500pp.

[2] AGENCE DE L'EAU (France). 1994."L'assainissement de l'agglomération. Technique d'épuration actuelles et évaluation étude inter agence "Avril 1994.

[3] Baccar R., M. Sarra, J. Bouzid, M. Feki, P.Blanquez. (2012). Removal of pharmaceutical compounds by activated carbon prepared from agricultural by-product. Chem. Eng. J. 211310317.

[4] Bhatnagar,Eva kumar,A.K Minocha,Byangdun jeon,Hachool Song, Yong-Chan Seo. (2009). “ Removal of anionic Dyes from water citrus limoniun(lemon)peel:Equilibrium studies and kinetic modeling" p316-334.

[5] Bhatnagara A., Minochaa A.K., Mika. S. (2010)."Adsorptive removal of cobalt from aqueous solution by utilizing lemon peel as biosorbent".Biochemical Engineering Journal, Vol. 48, pp. 181-186.

[6] Chun, W. G., and Chen, K. (2002). Test Results of a BiDirectional Thermodiode System for Solar Energy Utilization. Sol. Energy, 73 (4), pp. 269-280.

[7] Cooney, D.O., (1999). Adsorption Design for Wastewater Treatment. Lewis Publishers, Boca Raton, FL.

[8] Faouzia Benamraoui. (2014). " Elimination des colorants cationiques par des charbons actifs synthétisé à partir des résidus de l'agriculture" p24-90.

[9] Forgacs E, T. Cserhati, G. Oros. 2004. Removal of synthetic dyes from wastewaters: a review. Environ. Int. 953-971(2004).

[10] Joel Graindorge, Eic Landot, " La qualité de l'eau potable, techniques etresponsabilités » Territorial Editions, (2007).

[11] Khalfaoui A,. (2012). «Etude Expérimentale de L'élimination de Polluants Organiques et Inorganiques par Adsorption sur des Matériaux Naturels: Application aux Peaux d'Orange et de Banane »thèse, université mentouri de constantine, p20-106.

[12] Khormaei M., B. Nasernejed, M. Edrisi, T. Eslamzadeh.(2007). "Copper bio sorption from aqueous solution by Sour orange residue", Journal of Hazardous Material 149, 269 -274 .
[13] Lin, H., Hopmans, J. W., Richter, D. deB. (2011): Interdisciplinary Sciences in a Global Network of Critical Zone Observatories. Vadose Zone J., 10:781-785. . DOI: 10.2136/vzj2011.0084

[14] Manohar D.M., K. Anoop Krishnan, T.S. Anirudhan (2002). Removal of mercury(II) from aqueous solutions and chlor-alkali industry wastewater using 2-mercaptobenzimidazole-clay. https://doi.org/10.1016/S0043-1354(01)00362-1 .Water Res., 36 (2002), pp. 1609-1619.

[15] Mohan, D., Pittman, Jr C.U., Steele, P.H., (2006). Pyrolysis of Wood/Biomass for Bio-Oil A Critical Review. Energy Fuels, 20, 848-889. J. Colloid Interf. Sci.297, 489-504.

[16] Mouthe A (2017). Etude physico-chimique de l'adsorption du Crystal violet par le biosorbant et les charbons actifs des amandes des mangues. Thèse doctorat, spécialité chimie industrielle et environnement Université de Ngaoundéré pp100-201.

[17] Nour T. Abdel-Ghani1 and Ghadir A. El-Chaghaby (2014) "Biosorption for metal ions removal from aqueous solutions: A review of recent studies".

[18] Patil S.R. Shirsath , , R. Patil , J. B. Naik , P.R. Gogate. S.H Sonawane. (2013). Removal of Brilliant Green from wastewater using conventional and ultrasonically prepared poly (acrylic acid) hydrogel loaded with kaolin clay: A comparative study. Ultrasonics Sonochemistry 20914-923.

[19] Rais Ahmad (2009). Studies on adsorption of crystal violet dye from aqueous solution onto coniferous pinus bark powder (CPBP). J Hazard Mater. 2009 Nov 15:171(1-3):767-73. doi 10.1016/j.jhazmat.2009.06.060. Epub 2009 Jun 21. p4-7.

[20] Rais Ahmad, Shazia Haseeb (2017). Adsorption of $\mathrm{Pb}$ (II) on Mentha piperita carbon (MTC) in single and quaternary systems. Arabian Journal of Chemistry-ELSEVIER ; Volume 10, PP S412S421.

[21] Rangabhashiyam S., N. Anu, N. Selvaraj.(2013). Sequestration of dye from textile industry wastewater using agricultural waste products as adsorbents. Journal of Environmental Chemical Engineering, 629-641.

[22] Ryoo, R., Joo, S.H., Jun, S., (1999). Synthesis of Highly Ordered Carbon Molecular Sieves via Template-Mediated Structural Transformation. Materials Chemistry Laboratory, Department of Chemistry and Center for Molecular Science, Korea Advanced Institute of Science and Technology, Taejon, 305-701, Korea. J. Phys. Chem. B 103, 7743-7746.

[23] Sakr F., A. Sennaoui, M. Elouardi, M. Tamimi, A. Assabbane, (2014). Étude de l'adsorption du Bleu de Méthylène sur un biomatériau à base de Cactus (Adsorption study of Methylene Blue on biomaterial using cactus) p397-406.

[24] Samake Drissa (2008). « Traitement des eaux usées de tannerie à l'aide des matériaux

[25] à base d'argile » Thèse Doctorat PHD cotutelle entre Université Mali et Université de Lorraine -Nancy/ France P 20-120.

[26] Sayed Zia Mohammadia, Mohammad Ali Karimia, Sayedeh Nasibeh Yazdya, Tayebeh Shamspurb,* and Hooshang Hamidiana (2015). "Removal of pb(ii) ions and malachite green dye from wastewater by activated carbon produced from lemon peel'" P5-12.

[27] Senthilkumar, S., P. Kalaamani, K. Porkodi, P.R.Varadarajan and C.V. Subburaam (2006). Adsorption of dissolved Reactive red dye from aqueous phase onto activated carbon prepared from agricultural waste.Bioresour. Technol., 97 1618-1625.

[28] Shawabkeh,R.A and Tutunji,M.F.(2003). Experimental study and modeling of basic dye sorption by diatomaceaous clay.Applied Clay Science,p111-120,(2003).

[29] Wibowo N., Wibowo D., Setyadhi L., Setiawan J. (2017) Adsorption of Benzene and Toluene From Aqueous Solutions Onto Activated Carbon and Its Acid and Heat Treated Forms: Influence of Surface Chemistry on Adsorption. Journal of Hazardous Materials 146(1-2):237-42 - August 2007. 